\title{
KESIAPAN SEKOLAH DALAM IMPLEMENTASI PROGRAM FULL DAY SCHOOL (FDS) SD MUHAMMADIYAH DI KOTA YOGYAKARTA
}

\author{
Nur Hidayah \\ PGSD FKIP Universitas Ahmad Dahlan Yogyakarta \\ nur.hidayah@pgsd.uad.ac.id
}

\begin{tabular}{ll}
\hline $\begin{array}{l}\text { Informasi artikel } \\
\text { Sejarah artikel }\end{array}$ & \\
Diterima & $: 20 / 10$ \\
Revisi & $:$ I8 \\
Dipublikasikan & $: 28 / 12 / 2107$ \\
Kata kunci: & \\
kesiapan, & \\
Full Day School, \\
sekolah dasar
\end{tabular}
Penelitian ini bertujuan untuk mendeskripsikan kesiapan sekolah Muhammadiyah dalam implementasi program FDS dalam hal: I) Kesiapan kurikulum sekolah, 2) Kesiapan pendidik dan tenaga kependidikan. 3) Kesiapan peserta didik, 4) Kesiapan sarana prasarana, 5) Kesiapan pembiayaan

Penelitian ini adalah deskriptif kualitatif. Data primer diperoleh melalui wawancara terhadap kepala sekolah, guru dan siswa. Observasi untuk melihat kesiapan sekolah dalam implementasi program Full Day School. Tempat penelitian di SD Muhammadiyah Sokonandi, SD Muhammadiyah Bausasran, SD Muhammadiyah Tegalrejo dan SD Muhammadiyah Notoprajan sebagai sampel sekolah dengan tingkatan premium, gold dan silver.
Dari hasil penelitian menunjukkan bahwa SD di kota Yogyakarta telah siap dalam melaksanakan program Full Day School dengan lima hari sekolah. Rata-rata kepala sekolah mempunyai konsistensi yang tinggi dalam memimpin dan menanamkan karakter pada warga sekolah, serta memimpin dengan humanis. Guru SD Muhammadiyah kota Yogyakarta sudah siap dengan peran menjadi fasilitator, guru kelas, administator, evaluator, guru BK. Guru harus full time dan memberikan contoh karakter yang baik bagi siswa. Sekolah juga telah siap membiayai program ini diantaranya dengan sumber SPP siswa, dana bosnas, bosda, dan unit produksi yang ada disekolah. Rata-rata siswa telah siap melaksanakan program Full Day School ini dengan lima hari sekolah. Siswa merasa senang walaupun jam di sekolah semakin panjang

\author{
Key word: \\ readiness, \\ Full Day School, \\ elementary school
}

\section{ABSTRACT}

This research aims to describe the readiness of Muhammadiyah schools in the implementation of FDS program in terms of: I) readiness of school curriculum, 2) readiness of educators and education personnel, 3) readiness of students, 4) readiness of school infrastructure, and 5) readiness of school financial.

This research is descriptive qualitative. Primary data were obtained through interviews with principals, teachers and students. Observation to see school readiness in implementing Full Day School program. The research takes place at four Muhammadiyah elementary school as sample with premium, gold and silver level, there are: Sokonandi, Bausasran, Tegalrejo and Notoprajan Elementary School.

The research shows that Elementary Schools in Yogyakarta city are ready to implement Full Day School program with five days school. Most principal has high consistency in leading and cultivating character in the school community, as well as leading with humanists. Teachers are ready with their very important role as facilitator, classroom teacher, administator, evaluator, and counseling teacher. the teachers must work full time and must give good character examples for the students. The schools are ready to financing this program with the fund come from students' tuition, National and regional School Operational fund Support (BOSDA\&BOSNAS), and production units that exist in the schools. Most student are ready to implement this Full Day School program with five days school. Students feel happy even though the hours in school are getting longer 


\section{Pendahuluan}

Undang-undang Sistem Pendidikan Nasional dalam pasal I ayat I tersirat bahwa pendidikan adalah usaha sadar dan terencana untuk menyiapkan peserta didik melalui kegiatan bimbingan, pembelajaran, dan/atau latihan bagi peranannya di masa yang akan datang. Pendidikan sebagai suatu proses pengubahan sikap dan perilaku seseorang berlangsung melalui pembelajaran dan pelatihan. Pembelajaran dan proses pelatihan di Indonesia dapat dialami pada tiga sektor yaitu: formal, non formal dan informal. Ketiga sektor tersebut haruslah merupakan jaringan yang sangat kuat dan erat, sehingga pendidikan benar-benar mengarah pada pendewasaan, pengetahuan dan ketrampilan seseorang.

Dalam pencapaian orientasi pendidikan yang menjadikan peserta didik memiliki kedewasaan, pengetahuan, dan ketrampilan tersebut, Menteri Pendidikan dan Kebudayaan Bapak Muhadjir Effendy mencanangkan program full day school (FDS) terutama pada jenjang Sekolah Dasar agar peserta didik mendapat pendidikan karakter sebesar 80 persen dan untuk pengetahuan umumnya 20 persen, sehingga sistem belajar pada program FDS dianggap memungkinkan untuk diterapkan. Full day school adalah program sekolah di mana proses pembelajaran dilaksanakan sehari penuh di sekolah. Dengan kebijakan seperti ini maka waktu dan kesibukan anak-anak lebih banyak dihabiskan di lingkungan sekolah daripada di luar sekolah. Anak-anak dapat berada di rumah lagi setelah menjelang sore. Selain itu, agar anak tidak sendiri ketika orang tua mereka masih bekerja. Program FDS dilaksanakan melalui pendekatan Integrated Curriculum dan Integrated Activity. Pengembangan program ini dapat di lakukan melalui pengembangan kurikulum dan pengelolaan Kegiatan belajar mengajar oleh guru dan pengelola yayasan/ lembaga yang bersangkutan.

Berdasarkan Fakta Sekolah Dasar di Yogyakarta yang sudah menerapkan program FDS khususnya di SD Muhammadiyah Sapen Yogyakarta siswa merasa sengan dengan pembelajaran yang ada disekolah. Penerapan program FDS di SD Muhammadiyah Sapen Yogyakarta para siswa selama sehari penuh di sekolah. Mereka disediakan makanan ringan dan makan siang setiap harinya. Menurut informasi kepala sekolah Bapak Agung mengatakan bahwa FDS sudah diberlakukan sejak tahun 2016. Dari pukul 07.00-I4.00 WIB adalah waktu pelajaran yang ada di kurikulum, I4.30-I7.00 WIB ektrakulikuler. Konsep kegiatan ekstra kulikuler itu adalah kegiatan yang menyenangkan untuk siswa (Harian jogja.com, Selasa (9/8/2016).

Kualitas sumberdaya FDS dipilih dari guru-guru bidang studi yang profesional, berkualitas dan mempunyai integritas yang tinggi. Peningkatan kualitas tenaga kependidikan seperti tenaga kependidikan seperti tenaga ahli perpustakaan, laborat dan administrasi juga merupakan fokus dalam rangka mensupport penerapan program FDS. Program-program yang dikembangkan juga beragam dengan melibatkan komite sekolah, pengawas, pendidikan, pengurus musyawarah guru mata pelajaran. Pemanfaatan sarana prasarana pembelajaran dengan menggunakan Multimedia. Peningkatan mutu sarana dan prasarana pendidikan untuk peralatan dan ruang laboratorium yaitu laboratorium IPA, laboratorium bahasa, laboratorium komputer, laboratorium matematika, laboratorium IPS dan lainnya yang dapat menunjang pelaksanaan pembelajaran di sekolah tersebut. Kurikulum sekolah program full day school juga disiapkan sedemikian rupa untuk memacu keunggulan dalam aspek sains, keagamaan, bahasa berbasis informasi teknologi, muatan lokal, keterampilan-keterampilan, dan ekstrakurikuler dan pengembangan diri.

Berdasarkan tuntutan dalam implementasi program FDS tersebut. Di lingkungan Majelis Dikdasmen Pimpinan Daerah Muhammadiyah Kota Jogjakarta yang memiliki 36 SD Muhammadiyah tentunya kesiapan sekolah satu dengan yang lain tidaklah sama seperti yang dimiliki oleh SD Muhammadiyah Sapen. Oleh karena itu, penelitian ini bermaksud untuk memotret kesiapan sekolah dalam implementasi program FDS di SD Muhammadiyah Se Kota Yogyakarta.

Berdasarkan latar belakang diatas penulis mengajukan rumusan masalah yaitu Bagaimana kesiapan sekolah Muhammadiyah dalam implementasi program full day school di Kota Yogyakarta dilihat dari 
I. Kesiapan kurikulum sekolah

2. Kesiapan pendidik dan tenaga kependidikan

3. Kesiapan peserta didik sekolah

4. Kesiapan sarana prasarana sekolah

5. Kesiapan pembiayaan sekolah

\section{Metode Penelitian}

Pemilihan tempat penelitian yang dilakukan peneliti diperkuat oleh pendapatnya Moleong (2012:I65I66) yang mengatakan bahwa pada penelitian kualitatif tidak ada sampel acak, tetapi hanya ada sampel bertujuan. Di Kota Yogyakarta terdapat 36 sekolah yang sudah melaksanakan program Full Day School. Penelitian dilakukan pada 4 SD Muhammadiyah di Kota Jogjakarta.yaitu SD Muhammadiyah Bausasran, SD Muhammadiyah Tegalrejo, SD Muhammadiyah Notoprajan dan SD Muhammadiyah Sokonandi

Penelitian ini merupakan survey dengan menggunakan pendekatan kualitatif. Pemilihan pendekatan kualitatif didasarkan pada pertimbangan bahwa gejala dalam penelitian ini merupakan proses pengimplementasian program full day school (FDS) yang perlu dilakukan melalui kajian terhadap aktivitas pihak sekolah yang terlibat dalam kesiapan implementansi program FDS, dan secara konseptual program tersebut menggunakan konteks dan desain local sesuai dengan karakteristik lingkungan sekolah yang diungkap secara deskriptif. Dalam penelitian kualitatif, kehadiran peneliti diupayakan tidak mengubah suasana yang sudah ada.

\section{Hasil dan Pembahasan}

Secara umum semua sekolah di SD Muhammadiyah Kota Yogyakarta telah siap melaksanakan program Full Day School yang secara serempak dilaksanakan pada bulan Juli 2017. Berdasarkan hasil wawancara dengan kepala sekolah terkait dengan kesiapan sekolah dalam implementasi program Full day school adalah sebagai berikut :

"Untuk program Full Day School, sekolah sudah siap dengan adanya program Full Day School. Akan tetapi sekolah memiliki kendala, yaitu pengaturan jadwal mata pelajaran khususnya Penjas Orkes dari hari senin sampai hari sabtu karena selama 6 hari cukup untuk 6 kelas dari kelas I sampai kelas 6, kini dirubah menjadi dari hari senin sampai jum'at jadi, ada kurang satu kelas yang ditumpuk satu hari. Konsekuensinya sekolah menambah satu hari untuk 2 kelas mata pelajaran penjas orkes yang berbeda. Karena dilaksanakan siang hari, sekolah menyewa ruangan indoor agar siswa tidak kepanasan. Untuk kendala yang kedua yaitu dari segi mutu pelajaran kelas 6. Sebelum adanya Full Day School, kelas 6 ada program tambahan belajar. Dulunya kelas 4,5,dan 6 pulang jam 2 siang, guru tersebut bisa membantu guru s kelas 6 untuk pedalaman materi tambahan disekolah. Ketika 5 hari sekolah sulit untuk mengatur jadwal dan ruangan. Karena dulunya kelas 4,5,dan 6 pulang maka, kelas 6 yang menempatkan kelas yang kosong”

\section{Kesiapan Kepala Sekolah}

Keberhasilan manajemen sekolah sangat ditentukan oleh keberhasilan pimpinan (kepala sekolah) dalam mengelola tenaga kependidikan yang tersedia di sekolah. Dalam hal ini, peningkatan produktivitas dan repesentasi kerja dapat dilakukan dengan meningkatkan sumber daya manusia di tempat kerja melalui aplikasi konsep dan teknik manajemen personalia modern. 
Berdasarkan wawancara dengan kepala Sekolah di 4 SD Muhammadiyah Kota Yogyakarta yang meliputi SD Muhammadiyah Sokonandi, SD Muhammadiyah Bausasran, SD Muhammadiyah Tegalrejo dan SD Muhammadiyah Notoprajan terkait kepemimpinan sekolah dalam rangka Kesiapan dalam Program Full day School adalah sebagai berikut :

a. Seorang kepala sekolah harus mempunyai konsistensi yang tinggi dalam semua kegiatan sekolah baik berupa rencana dan aksi. Seorang kepala sekolah juga harus memberikan contoh baik untuk dicontoh oleh warga sekolah, kepala sekolah menjadi seorang teladan

b. Kepala sekolah harus memimpin dengan baik dan lebih humanis yaitu memimpin dengan hati. Kepala sekolah sering melakukan komunikasi dalam rapat dengan guru-guru untuk mengevaluasi kegiatan yang sudah berjalan.

c. Kepala sekolah sudah memimpin sangat bagus dan kepala sekolah full tidak mengajar, hanya kalau ada jam kosong saja.

d. Kesiapan sekolah tidak menjadi masalah. Karena sekolah sudah menjalankan program Full Day School semenjak tahun 2000 sebelum ditugaskan di sekolah sekarang. Kepala sekolah juga menerapkan program kehadiran dan kepulangan untuk guru dan mendapatkan reward dan punnishment. Yang pertama guru disiplin untuk kedatangannya dari jam $06.00-06.25$ dan mendapatkan reward 10.000 per hari, yang kedua guru kurang disiplin yaitu kehadirannya dari jam 06.25 - 06.40 akan mendapatkan reward 5000 per hari, sedangkan yang terakhir adalah guru tidak disiplin kehadirannya diatas jam 07.00 dan mendapatkan punnisment dendan 2.500 .

\section{Kesiapan tenaga pendidikan}

Manajemen tenaga kependidikan atau manjemen personalia pendidikan bertujuan untuk mendayagunakan tentang kependidikan secara efektif dan efisien untuk mencapai hasil yang optimal, namun tetap dalam kondisi yang menyenangkan. Manajemen tenaga kependidikan mecakup (I) perencanaan pegawai, (2) pengadaan pegawai, (3) pembinaan dan pengembangan pegawai, (4) promosi dan mutasi, (5) pemberhentian pegawai, (6) kompensasi, dan (7) penilaian pegawai. Semua itu perlu dilakukan dengan baik dan benar agar apa yang diharapkan tercapai, yakni tersedianya tenaga kependidikan yang diperlukan dengan kualifikasi dan kemampuan yang sesuai serta dapat melaksanakan pekerjaan dengan baik dan berkualitas (Mulyasa, 20I2: 43)

Tugas kepala sekolah dalam kaitannya dengan pengelolaan tenaga kependidikan bukanlah pekerjaan yang mudah karena tidak hanya mengusahakan tercapainya tujuan sekolah, tetapi juga tujuan tenaga kependidikan (guru dan pegawai) secara pribadi. Karena itu kepala sekolah dituntut untuk mengerjakan instrumen pengelolaan tenaga kependidikan seperti daftar absensi, daftar urut kepangkatan, daftar riwayat hidup, daftar riwayat pekerjaan, dan komitmen pegawai untuk membantu kelancaran manajemen sekolah di sekolah yang dipimpinnya.

Berikut adalah hasil wawancara dengan kepala sekolah terkait dengan kesiapan guru dalam implematasi program full day school

"Untuk beban tugas guru menjadi tambahan awalnya guru mengeluh, tapi seiring berjalannya waktu tidak menjadi masalah. Sehingga, beban mengajar guru menjadi 8 jam per hari."

“...Peran guru tentunya sangat penting menjadi fasilitator, guru harus full time dan harus memberikan contoh karakter yang baik bagi siswa. Guru menjadi, gru kelas, administator, evaluator, guru BK."

“...Peran guru dalam melaksanakan fullday school guru harus mempunyai rasa sami'nah yaitu ikhlas karena gaji yang diberikan oleh guru tidak sebanding dengan apa yang dikerjakan di lapangan. Menjadi seorang teladan dan insidental. Mampu 
mempromosikan sekolah dalam mencari murid dengan cara memberikan brosur atau power point slide show ke TK dan mengundang anak TK ke sekolah yang merupakan salah satu program dari sekolah yaitu gebyar TK."

“...Peran guru tentunya sangat penting karena,guru harus memberikan contoh karakter yang baik bagi siswa. Guru menikmati dan enjoy saja dengan adanya Full Day School."

Hasil wawancara dengan guru terkait dengan kesiapannya dalam implementasi program full day school.

"Peran guru tentunya sangat penting karena, guru harus full time dan harus memberikan contoh karakter yang baik bagi siswa. Supaya pembelajaran tidak merasa jenuh, dalam pembelajaran guru menggunakan metode yang menarik serta menggunakan media yang nyata agar siswa tidak mudah merasa bosan dalam pembelajaran (BS)"

“...Peran guru sangat penting. Untuk pembelajaran dari jam 7 pagi sampai jam 3 sore, tetapi ada hari yang kita berhentikan sampai jam 2,kemudian dilanjutkan kegiatan ekstrakurikuler seperti Tapak suci, dan HW. Sedangkan untuk hari jum'at ekstrakurikuler dilakukan jam 4 sore.Jadi, tidak masalah dan tidak menganggu jadwal yang lain.”

“...Untuk awal berjalan program Full Day School itu melelahkan karena belum terbiasa tapi sekarang sudah terbiasa ,jadi tidak masalah lagi dengan adanya program Full Day School.”

"Guru mengawal betul keadaan kondisi siswa, karena disini guru bertugas sebagai guru kelas yang harus memahami kebutuhan-kebutuhan siswa."

\section{Kesiapan Kesiswaan}

Siswa merupakan bagian penting dari sekolah dan agar tidak terjadi keruwetan dalam melaksanakan kegiatan pengajaran, maka perlu diadakan penelahaan tentang siswa. Hal ini berkaitan dengan dasar pertimbangan dalam pengembangan suatu perencanaan pengajaran, seperti : menentukan jenis, luas dan bobot bahan pengajaran yang akan disajikan, cara penyampaian yang akan dilakukan dan kegiatankegiatan belajar lainnya (Hamalik, 2013:38)

Mulyasa (2012:46) menjabarkan tanggung jawab kepala sekolah dalam mengelola bidang kesiswaan berkaitan dengan hal-hal berikut :

a. Kehadiran murid di sekolah dan masalah-masalah yang berhubungan dengan itu;

b. Penerimaan, orientasi, klasifikasi, dan penunjukkan murid ke kelas dan program studi;

c. Evaluasi dan pelaporan kemajuan belajar;

d. Program supervisi bagi murid yang mempunyai kelainan, seperti pengajaran, perbaikan, dan pengajaran luar biasa;

e. Pengendalian disiplin murid;

f. Program bimbingan dan penyuluhan;

g. Program kesehatan dan keamanan;

h. Penyesuaian pribadi, sosial, dan emosional.

Berikut hasil wawancara kepala sekolah terkait kesiapan siswa dalam implementasi full day School: 
“..'Untuk siswa awalnya mengeluh karena merasa kelelahan tapi sekarang tidak karena sudah terbiasa. Sekolah juga sudah menyiapkan katering untuk makan siang setiap siswa."

"Siswa menanggapi baik-baik saja karena di dalam program Full Day School siswa menjaadi objek dan subjek mereka pelakunya. Siswa kadang ada yang sakit hanya karena belum sarapan saja.”

"Sekolah sudah mempunyai aturan sendiri untuk dilaksanakan oleh siswa, aturan itu harus ditaati. Untuk kelas 6 siswa wajib mengikuti ekstrakulikuler HW untuk kelas bawah siswa mengikuti ekstrakulikuler akademik. Siswa juga mengikuti les tambahan setelah mengikuti jam aktif belajar. Siswa sudah mendukung dalam mengimplementasikan program fullday dengan siswa mengikuti proses pembelajaran di kelas."

"Siswa menanggapi baik-baik saja karena di dalam program Full Day School siswa tidak ada masalah. Siswa bisa mengikuti kegiatan ekstrakurikuler seperti HW dan iqra."

Hasil wawancara guru terkait kesiapan siswa dalam implementasi full day School

"Siswa menanggapi baik-baik saja karena di dalam program Full Day School siswa tidak sepenuhnya belajar seharian, tetapi dapat mengikuti penanaman pendidikan karakter dan juga siswa mengikuti kegiatan ekstrakurikuler seperti HW, Tari, Drumband, Tapak Suci, dll.”

"Untuk respon siswa tidak ada yang protes dan berjalan dengan lancar."

"Untuk siswa kelas tiga mereka menyukai program Full Day School dan malah ingin pulang lebih lama seperti jam 4. Dan menyukai lingkungan sekolah, ada juga orang tua yang kerja pulang sore mungkin dari faktor tersebut siswa ingin pulang lebih sore. Untuk program ekstrakurikuler ada tapak suci,seni tari, drumband. Untuk kelas 3 setiap hari selasa adanya Tahfidz. Untuk hari rabu ada tapak suci, hari kamis ada HW dan hari jum'at ada seni tari."

"siswa cukup enjoy dan tetap senang walaupun diadakan program Full Day School, siswa tidak ada yang mengeluh mereka tetap menikmati."

Hasil wawancara siswa terkait implementasi full day School

“..Untuk siswa awalnya mengeluh karena merasa kelelahan tapi sekarang tidak karena sudah terbiasa. Sekolah juga sudah menyiapkan katering untuk makaN siang setiap siswa. Peran siswa yaitu melaksanakan aturan peraturan yang sudah ditetapkan oleh sekolah dengan baik dan benar. Siswa mengaku capek dalam implementasi program Full Day School ini tetapi mereka cukup senang karena dapat bermain bersama teman-teman disekolah. Sehingga rasa capek tidak mereka rasakan saat bisa bermain dengan teman."

4. Kesiapan pembiayaan

Keuangan dan pembiayaan merupakan salah satu sumber daya yang secara langsung menunjang efektivitas dan efisiensi pengelolaan pendidikan. Hal tersebut lebih terasa dalam manajemen sekolah, yang menuntut kemampuan sekolah untuk merencanakan, melaksanakan dan mengevaluasi serta mempertanggung jawabkan pengelolaan dana secara transparan kepada masyarakat dan pemerintah. 
Dalam penyelenggaraan pendidikan, keuangan dan pembiayaan merupakan potensi yang sangat menentukan dan merupakan bagian yang tak terpisahkan dalam kajian menajemen pendidikan. Komponen keuangan dan pembiayaan pada suatu sekolah merupakan komponen produksi yang menentukan terlaksananya kegiatan-kegiatan proses belajar-mengajar di sekolah bersama komponenkomponen lain. Dengan kata lain setiap kegiatan yang dilakukan sekolah memerlukan biaya, baik itu disadari maupun tidak disadari.

Mulyasa (2012:48), sumber keuangan dan pembiayaan pada suatu sekolah secara garis besar dapat dikelompokkan atas tiga sumber, yaitu (I) pemerintah, baik pemerintah pusat, daerah maupun keduaduanya, yang bersifat umum atau khusus dan diperuntukkan bagi kepentingan pendidikan; (2) orang tua atau peserta didik; (3) masyarakat, baik mengikat maupun tidak mengikat.

Berkaitan dengan penerimaan keuangan dari orang tua dan masyarakat ditegaskan dalam UndangUndang Sistem Pendidikan Nasional 1989 bahwa karena keterbatasan kemampuan pemerintah dalam pemenuhan kebutuhan dana pendidikan, tanggung jawab atas pemenuhan kebutuhan dana pendidikan merupakan tanggung jawab bersama antara pemerintah, masyarakat, dan orang tua. Adapun dimensi pengeluaran meliputi biaya rutin dan biaya pembangunan.

Berikut hasil wawancara kepala sekolah terkait kesiapan keuangan dalam implementasi full day School

"Dari sisi keuangan tidak ada masalah. Dana berasal dari BOSDA, BOSNAS, dan SPP. Sekolah ada dana rutin bulanan berasal dari SPP dan ketering sedangkan rutin tahunan yaitu biaya kegiatan tahunan sekolah misalnya outbond, outclass, dan peringatan hari besar yang dibayar diawal. Selain itu ada perlengkapan sepertu buku dan seragam. Sedangkan uang pangkal yaitu infak selama 6 tahun yang dibayar di kelas satu dibebankan 6 juta per siswa."

"Dari keuangan siap gak siap harus siap. Saya menggunakan uang seadanya uang saya cukupkan. Sumber keuangan dari SPP siswa, dari kantin, kerja sama dengan inti media penjualan kaos mendapatkan untung 1000.000 perbulan, dan mencari proposalproposal. Dari JPD, dan ada BOSDAS Swasta yang dari pemerintah."

"Secara administrasi sekolah harus mempunyai guru lalu mengevaluasi guru, untuk perubahan kurikulum ini guru membutuhkan waktu untuk beradaptasi. Sekolah mengawali pembelajaran dari jam 6.45 WIB sampai jam I5.I0 WIB"

"Siswa membayar uang sumber pelaksanaan pendidikan sebesar Rp II0.000,- dan ditambah uang catering."

"Sekolah menerima uang dari dana BOS, dan mengajukan proposal ke PDM. Sekolah mempunyai kantin, koperasi dan SD Muh Bausasran Mart (MUBAYO Mart)."

"Sumber keuangan dari SPP siswa dan biaya operasional dari pemerintah. Sumber biaya lain dari peningkatan mutu, ada juga dari BOS Nasional dan BOS Daerah, dari PDN juga memberikan kontribusi untuk tambahan gaji guru.”

5. Kesiapan sarana dan prasarana

Sarana dan pendidikan adalah peralatan dan perlengkapan yang secara langsung dipergunakan dan menunjang proses pendidikan, khususnya proses belajar mengajar, seperti gedung, ruang kelas, meja kursi, serta alat-alat dan media pengajaran. Adapun yang dimaksud dengan prasarana pendidikan adalah fasilitas yang secara tidak langsung menunjang jalannya proses pendidikan atau pengajaran, seperti halaman, kebun, taman sekolah, jalan menuju sekolah, tetapi jika dimanfaatkan secara langsung untuk proses belajar mengajar, seperti taman sekolah, halaman sekolah sebagai sekaligus lapangan olah raga, komponen tersebut merupakan sarana pendidikan . 
Manajemen sarana dan prasarana yang baik diharapkan dapat menciptakan sekolah yang bersih, rapi, indah sehingga menciptakan kondisi yang menyenangkan baik bagi guru maupun murid untuk berada di sekolah. Di samping itu juga diharapkan tersedianya alat-alat atau fasilitas belajar yang memadai secara kuantitatif, kualitatif, dan relevan dengan kebutuhan serta dapat dimanfaatkan secara optimal untuk kepentingan proses pendidikan dan pengajaran, baik oleh guru sebagai pengajar maupun muridmurid sebagai pelajar (Mulyasa, 20I2:49).

Berikut hasil wawancara siswa terkait kesiapan sarana dan prasarana dalam implementasi full day School:

"Kesiapan sudah cukup memadai dari segi ruang belajar/ kelas. Perpustakaan sudah ada dan buku-buku juga sudah cukup lengkap. Tetapi laboratorium belum ada karena di SD Muhammadiyah Tegalrejo terbatas tempat. Upacara saja warga sekolah memakai jalan didepan sekolah. Dan untuk olahraga pihak sekolah bekerja sama dengan Monumen Diponegoro.”

“..Untuk sarana dan prasarana sekolah sudah cukup memadai semua."

“...sarana prasarana yang ada di SD Muh Notoprajan sudah mendukung berjalannya program Full Day School, bisa dilihat dari ruang kelas yang dirasa sudah cukup enak ditempati oleh siswa-siswa. Terdapat pula perpustakaan yang buku-bukunya sudah cukup lengkap dan laboraturium."

“...Menurut bapak kepsek untuk sarpas kamar mandi cukup soalnya dari pagi sampai sore harus mencukupi jumlah siswanya. Untuk LHS membutuhkan makan dari sekolah menyediakan catering, kepala sekolah menyerahkan sepenuhnya kepada wali murid agar siswa membawa bekal dari rumah. Kalau dari ruang belajar memenuhi yang tidak memenuhi ruang perustakaannya. Untuk laboratoriumnya sudah ada alat peraganya."

\section{Kesimpulan}

Berdasarkan hasil temuan pada penelitian ini maka dapat ditarik suatu kesimpulan bahwa di SD Muhammadiyah kota Yogyakarta pada dasarnya telah siap untuk implementasi program Full Day School. Hal ini dapat diketahui dari kesiapan pada dua dimensi yaitu:

I. Dimensi perangkat kurikulum. Perangkat kurikulum yang digunakan seperti silabus, RPP sudah disesuaikan dengan lima hari sekolah

2. Dimensi sarana dan prasarana. Sarana dan prasarana yang ada rata-rata sudah memadai Ruang kelas dan kantor dengan kondisi bagus, tersedianya sarana yang membantu kegiatan belajar mengajar pada tiap kelas yang juga dalam kondisi bagus, jumlah dan jenis laboratorium. jumlah buku di perpustakaan, dan mempunyai tempat kesehatan (UKS).

3. Dimensi Keuangan. Sumber dana pendidikan rata-rata di SD muhaamdiyah Kota Yogyakarta adalah dana BOS, BOSDA, BOSNAS, SPP siswa, dan unit produksi yang ada disekolah.

4. Dimensi kepemimpinan kepala sekolah. Dari kepemimpinan kepala sekolah di SD Muhammadiyah Yogyakarta telah siap dalam implementasi program Full Day School diantaranya mereka mem harus mempunyai konsistensi yang tinggi dalam semua kegiatan sekolah baik berupa rencana dan aksi. Seorang kepala sekolah juga harus memberikan contoh baik untuk dicontoh oleh warga sekolah, kepala sekolah menjadi seorang teladan

5. Dimensi Guru. Berkaitan dengan peran guru dalam implementasi program Full Day School di SD Muhammadiyah Kota Yogyakarta mencakup: 
a. Peran guru tentunya sangat penting karena, guru harus full time dan harus memberikan contoh karakter yang baik bagi siswa. Supaya pembelajaran tidak merasa jenuh, dalam pembelajaran guru menggunakan metode yang menarik serta menggunakan media yang nyata agar siswa tidak mudah merasa bosan dalam pembelajaran

b. Untuk pembelajaran dari jam 7 pagi sampai jam 3 sore, tetapi ada hari yang kita berhentikan sampai jam 2,kemudian dilanjutkan kegiatan ekstrakurikuler seperti Tapak suci, dan HW. Sedangkan untuk hari jum'at ekstrakurikuler dilakukan jam 4 sore.Jadi, tidak masalah dan tidak menganggu jadwal yang lain.

c. Guru mengawal betul keadaan kondisi siswa, karena disini guru bertugas sebagai guru kelas yang harus memahami kebutuhan-kebutuhan siswa. (SK)

6. Dimensi Kesiapan Siswa Kaitannya dengan kesiapan siswa jika diberlakukan kurikulum berbasis kompetensi secara umum mengatakan siap dengan kebijakan dan program sekolah.

\section{Referensi}

Dadi Permadi, 2009. Kepemimpinan Mandiri (Profesional) Kepala Sekolah. Bandung : PT. Sarana Panca Karya

Depdiknas, 20I I. Manajemen Peningkatan Mutu Berbasis Sekolah. Diknas-

Dirjen Pendidikan Dasar dan Menengah Direktorat Pendidikan Menengah Umum

E. Mulyasa, 2012. Manajemen Berbasis Sekolah Konsep Strategi dan Implikasi. Bandung: PT Remaja Rosda Karya

Hasan Hafidz, 2009. Dasar-dasar Pendidikan dan Ilmu Jiwa. Solo : CV Ramadhani

Lexy J. Moleong, 2012. Metodologi Pendidikan Kualitatif. Bandung : PT Remaja Rosdakarya

M. Ngalim Purwanto, 2012. Administrasi dan Supervisi Pendidikan. Bandung: PT Remaja Rosdakarya

Matthew B. Miles and A. Michael Huberman, 1992. Qualitative Data Analysis (terjemahan). Jakarta: UI Press.

Nanang Fattah, 2010. Ekonomi dan Pembiayaan. Bandung : PT Remaja Rosdakarya.

2010. Landasan Manajemen Pendidikan. Bandung: PT Remaja Rosdakarya. 